\title{
The Civilization Slept in the Land --The Outlook on Heritage and Innovation of Folk Art from the Xiao Guo Clay Sculpture
}

\author{
Yanqing Hou \\ School of Feixian, Linyi University, Feixian, Shandong, 273400, P.R. China \\ lydxmfl@126.com
}

\begin{abstract}
Xiao Guo clay sculpture in the city of Cang shan is the outstanding representative in the Chinese folk sculpture art. Meantime it can also be known by foreigners as the most folk artistic handwork full of the oriental color. This article is mainly illustrated from three aspects, which is the unique style of Xiao Guo clay sculpture, its heritage dilemma in development and the choice of creation rooted intradition. The article is trying to use objective and rational way to show the fact that only when rooted in tradition can Xiao Guo clay sculpture get the protection and heritage in the real sense.
\end{abstract}

Index Terms -Clay sculpture, Five--color, Heritage, Innovation.

\section{Introduction}

As the Intangible Cultural Heritage at National Level, Xiao Guo clay sculpture in the city of Cangshan village has gained the wide attention of experts and scolars at home and abroad in recent years, and its relevant research has also got fruitful achievements. For example, Dr.Gu Hao majoring in philosophy in the Tsinghua University, a visiting scholar in Valdosta State University made the detailed record on the production art in his works named Travel far and wide. Another way of Cangshan Xiao Guo clay. The article made by Zheng Hannong and Zuo Ailian made the study on the history and current status of Xiao Guo clay sculpture in their works named Cangshan Guo Ni toys. Unfortunately, most papers made by former scholars just focus on the skills, history and current status of Xiao Guo clay sculpture and are simply referred to its folk nature, heritage and protection during the study of traditional culture. Based on the former study, this article makes the further study on the Xiao Guo clay sculpture in terms of its aesthetic value of folk art and its folk connotation. Meanwhile this article is based on the protection of tradition and provides new thoughts on the heritage and development of Xiao Guo clay sculpture.

As one of the oldest art form in humanity, folk clay sculpture has its own independent style and aesthetic characteristics. The real life and the best wishes the ordinary people have can be illustrated through its own unique artistic nature and primary lifestyle. Xiaoguo village in Linyi is known for the production of clay sculpture. Cangshan handbook once wrote that the village of Xiao Guo in Cangshan city is the origin of clay sculpture toy, from the Qing Dynasty, especially the emperor Xianfeng period (1851). Li Xianzhi's grandfather, the late clay sculpture artist, studied clay art in Tianjin. In order to support the family, he mastered the skills of sculpture and used the local clay to sculpture the livestock first, and then dry and coat color to make sales in fairs. [1, 2] The true portrayal of people selling clay figures at that time can be vividly reflected in the proverb which said that Xiao Guo was busy making statues and then sold on all sides far from their homes, only left the statue figures crying out. [3]

Xiao Guo clay sculpture originated in the Xiao Guo village of Cangshan city in Shandong province and appeared during the period of emperor Xianfeng in Qing Dynasty, which has a long history of more than one hundred years. Xiao Guo clay sculpture's artistic charm including the unaffectedness and naturalness has made itself rank among the country of folk art in China. Especially nowadays this clay sculpture has its own unique style and complete shape, which turns out to be exaggerated, expressive, simple but not vulgar. The reason why most clay figures are so popular with children is that the productions of these clay figures are drawn from the real life. For example, the head of kinds of dolls are usually be exaggerated to turn out to be childlike, which is the important way used by the traditional artist to make look the like.Your goal is to simulate the usual appearance of papers in IEEE conference proceedings. For items not addressed in these instructions, please refer to the last issue of your conference's proceedings for reference or ask your conference Publications Chair for instructions.

\section{Xiao Guo Clay Sculpture Has the Unique Style Color}

On the one hand, it has the characteristics in common with the north of China, such as white, molding, and painting, etc. On the other hand, its style, color and material are also closely connected with the local production, climate and custom which reflect the distinctive personality. Xiao Guo clay sculpture is based on the color of pink and green, which looks warm, lively and bright. Meanwhile the bottom and back of some sculptures expose the real color of mud, which shows the great wisdom of the working people in ancient times. When it comes to the production method, the director of the culture of station in Xingming town explains that Xiao Guo clay sculpture used the local materials first be made with the clay molding and then outlined the white color following the color of red, pink and yellow, etc. At last, used by the outline of black, the clay sculpture revived in performance the emotions and expression of life .When made up with color, the back and bottom of clay 
sculpture should come out the nature of mud, carelessly at first glance, deliberately in essence. [3,4]

On the painting, Xiao Guo clay sculpture puts emphasis on the integration of painting and modeling, which is the socalled one third of process is given to modeling and one seventh is painting. In color, in addition to the basic white color as the outline, the folk artists in the city of Cangshan only use the color of pink, brilliant yellow, green complemented by black, which depict "pink and leaves" by the local people. [5]. A variety of different types of clay have different colored order, but the overall basic sequence is followed in turn by white, black, red, green, yellow .

Under the impact of commodity economy, the folk artists around the country alter the change of color to improve their embarrassing condition and to meet market needs. Now the traditional use of magenta is widely replaced by gouache and acrylic painting, which is making the painting color change a lot. Though magenta is easy to fade and fall off, Xiao Guo clay sculpture still insists on the use of the traditional magenta named "fuchsine" in the folk. From the result of color, this traditional painting has the irreplaceable value the modern painting can not possess. Firstly, traditional painting is clear and transparent. Secondly, the use of magenta dissolved in water can be well-written, and can't be shown in a sense of stagnation when painted by the adhesive pigments such as gouache, acrylic, paint, etc. With the change of lifestyle and the reduction of demand in many areas, the paint of magenta is becoming more and more uncommon.

Generally speaking, white as the background color first appears in the color of Xiao Guo clay sculpture, and then the line drawing on the clay is used by the artists with a brush. The functions of black lines on a white mud embryos can be shown as follows: the first function is to divide the structural form. Black lines is particular important because clay body usually can be handled in blur and subtleness in order to be stripped away from the mold. The second is to have internal decoration. Red and green which can endow the inherent color objects show in the nature are the base and the most dynamic color of the Xiao Guo clay sculpture. The dural property of expression and symbolization can be manifested in the same clay sculpture when these two colors are overlapped during the process of applying color. Yellow which plays the role of mixtion is the last complement. It can be used as the expression of particular object, only just used as the decorative color. Red and green are complementary colors, and the white and black are also in the same state. Especially the contrast of red and green are too strong and assertive. The application of five colors can greatly reduce the kinds of painting and extremely optimize its process.

According to the analysis of color lightness, the five colors of blue, yellow, red, white and black used in the Xiao Guo clay sculpture have the transition from the deepest black to the white light. Black and white colors are the poles, and the others such as red, green, yellow are gray colors of paint which form the unique style and reasonable structure in the sketch relations.

\section{Having Difficulty in Taking Every Step Towards Inheritance}

Though Xiao Guo clay sculpture has a history of more than one hundred years and has been known on all sides, the problems such as the time-consuming and rough process, economic backwardness, the lacking of successors and the plight of the shrinking market have a great influence on its development. From what's mentioned above, this kind of folk art will be doomed to disappear if effective measures should not be taken immediately. As the field of art produced in relatively closed and conservative rural areas, the means of inheritance mainly includes family instruction and non-family instruction. [6].Family instruction generally means that only the son inherits his father's work in the inside of family, and hands down to the next generation so as to maintain the superiority of a particular skills in the family .Non-family instruction shows that apprentice can get the skills from his master and then pass down its heritage. But the limitation brought by this way of heritage is that the master may secretly preserved the unique skills and miss these kinds of art if they happen to meet an accident, which can have the bad influence on the folk art. In the survey, we can learn from the artists in the village of Xiao Guo that few people take the learning of folk skills as a major, because it is becoming more and more difficult to support the family for the time being. Just taking the art of clay sculpture for example, there are only four households continuing to produce the clay sculpture and the youngest among them is the 70-year-old man named Liu Xiangfu. And the others are those who are more than 80 years old and can't find any inheritor. The artist in the local area is less than five households if Yin Fangli in the neighboring village is not included. Under such uncomfortable circumstance, no one knows how much economic benefit these clay artist can get and how far they can go without the driven interest.

With the improvement of its awareness and the support of government policy, commercial value of the Xiao Guo clay sculpture has become more and more conspicuous in recent years. It's good thing for the development and heritage of clay sculpture when some farmers discover its profits and open a large-scale workshop at home. However, the artistic characteristics of folk art will be greatly reduced because of the large-scale production of assembly line. The social, primitive and manual characteristics are the best selling points underlying the clay sculpture. The pipelined mode of production of course violates the nature and environment of folk art, which will surely lost the folk feature and make it hard to rise to artistic expression and pursuit of the realm. [7].achieve causes the loss of civil resistance This is tragedy not only for the innovation of folk art, but also for the progress of era.

\section{Innovation is Rooted in the Tradition.}

The aim of the protection of folk art is to inherit and restore those traditional skills and art form. The folk art should be protected and rescued especially in today's change or 
disappearance of traditional custom. Just as the proverb which says that with the skin gone, to what can the hair attach itself? So the best way is to be taken into museum. Meanwhile, It's important to protect the old folk artists of great talent and take measures to improve the social status of old artists in order to teach their students skills attentively. [8].It's essential that inheritor should maintain and use the traditional skills to make products with the traditional process, materials, shape and pattern. As a mirror of human history, folk handcraft is only the hand-made products without local characteristics.

Innovation should be in line with the aesthetic and custom of contemporary people. Its importance is to reenter the market, prolong and extend its vitality. According to the survey made by the author, the folk art tend to have two directions in the future: one is to go back to the folk custom. For example, the process of clay sculpture in Xiaoguo village still use the traditional pigments and handicrafts. Another is to break away from the folk custom, emphasizing the traditional folk art. For example, the artist in Xiaoguo village create a new way to inherit the tradition, that is put the clay sculpture into the delicate box and give the guests as the present.

As the time goes by, the form of expression of folk art is changing. But its change should be based on the tradition and local culture. [9].Folk color is one of the elements of art in the folk, and only folk color can highlight the folk characteristics. Xiao Guo clay sculpture is the successful example of using folk color. People are fascinated and mad about the festivity of the five colors, for example, black lines show the structure, red symbolizes auspiciousness, bright green means the natural peace and the yellow represents the lucky wealth, which are contrasting to the pure and sacred white.

Folk Art should retain more basic nature of art during the period of its occurrence and the cultural spirit the original art reflects in miscibility. When answering the question put forward by the reporter of the China Youth Daily, Professor Chen Hanmin, in the Academy of Art and Design, Tsinghua University, said that we want innovation and we still adhere to the national things at the same time. This sentence is good enough to apply to the innovation of folk art.

Folk art determining the market value and the price is the bearer of the humanistic power and the cultural background in the homegrown land. And the so-called creation that can break away from the native culture must not withstand the refinement of the common people and the test of time.

\section{Summary}

The article is trying to use rational way to show the fact that only when rooted in tradition can Xiao Guo clay sculpture get the protection and heritage in the real sense.

\section{References}

[1] Compilation committee of Cangshan county office, Cangshan County History, Zhonghua Book Company, Beijing, China, 1998. (In Chinese)

[2] Cangshan County People's Political Consultative Conference National Committee of Cultural and Historical Data, Highlights of Cangshan cultural and historical data, Shandong Map Publishing House, Jinan, China, 2003. (In Chinese)

[3] Cangshan county Party Committee Propaganda Department, Cangshan culture / customs volume, Shandong literature and Art Publishing house, Jinan, China, 2010. (In Chinese)

[4] H.N. Zheng, A. L. Zuo, Cangshan Guo Ni toys, Folklore Studies,1994,3. (In Chinese)

[5] H. Gu, Travel far and wide. Another way of Cangshan Xiao Guo clay, China Light Industry Press, Beijing, China, 2013. (In Chinese)

[6] Z.b. Tian, Introduction to arts and crafts, Knowledge Press, Shanghai, China, 1991. (In Chinese)

[7] L.H. Wang, China toys art history, Hunan Fine Arts Publishing House, Changsha, China, 2006. (In Chinese)

[8] J. Hang, China technological aesthetics history, People's Fine Arts Publishing House, Beijing, China, 2007. (In Chinese)

[9] Z.L. Jin, The tree of life and China folk art, Guangxi Normal University press, Guilin, China, 2002. (In Chinese) 